\title{
ENVIRONMENTAL PLANNING OF ABANDONED QUARRIES REHABILITATION - A METHODOLOGY
}

\author{
Hagiou Eleonora ${ }^{1}$, Konstantopoulou Garyfalia ${ }^{2}$ \\ ${ }^{1}$ Institute of Geology and Mineral Exploration (I.G.M.E.), Olympic Village, Thrakomacedones \\ GR 13677 Acharnes, Athens, GREECE, Mining Engineer, Dpt of Mineral Exploration \\ and Technoeconomical Studies, e-mail:norahagiou@igme.gr \\ ${ }^{2}$ Institute of Geology and Mineral Exploration (I.G.M.E.), Olympic Village, Thrakomacedones \\ GR 13677 Acharnes, Athens, GREECE, Dpt of Engineering Geology, e-mail: kongar@igme.gr
}

\begin{abstract}
Restoration of abandoned quarry sites has been for quite a few years practiced in various places in Greece, mainly in the broader district of Athens, a wide range of rehabilitation solutions has been used by the local authorities in order to cover basic needs of the population (cultural and athletic centres, municipal storage and parking facilities for heavy vehicles, open theatres, municipal waste facilities, cemeteries etc.). Still restoration of abandoned quarries (aggregate material, marble, industrial minerals etc) remains a major problem for almost every prefecture and has to be solved gradually due to lack of the necessary funds, solving the most acute environmental problems and covering basic needs of the population for municipal facilities.

In this paper the development of a methodology is presented for the elaboration of a priority list for the restoration/rehabilitation of numerous abandoned quarries comprised in a geographical or administrative entity. Using multi-criteria analysis and geographical information system we have concluded in a quick and cost effective method for the hierarchical classification of restoration sites. The establishment of an adequate set of criteria for the priority list is of main importance for the successful application of the method.
\end{abstract}

Key words: Restoration, abandoned quarry, rehabilitation, multi-criteria analysis, hierarchical classification.

\section{Introduction}

Restoration of abandoned quarry sites has been for quite a few years practiced in various places in Greece, mainly in the broader district of Athens, a wide range of rehabilitation solutions has been used by the local authorities in order to cover basic needs of the population (cultural and athletic centres, municipal storage and parking facilities for heavy vehicles, open theatres, municipal waste facilities, cemeteries etc.). Still restoration of abandoned quarries (aggregate material, marble, industrial minerals etc) remains a major problem (Figs $1 \& 2$ ) for almost every prefecture and has to be solved gradually due to lack of the necessary funds, solving the most acute environmental problems and covering basic needs of the population for municipal facilities (Fig. 3.).

In this paper the development of a methodology is presented for the elaboration of a priority list for the restoration/ rehabilitation of numerous abandoned quarries comprised in a geographical or ad- 


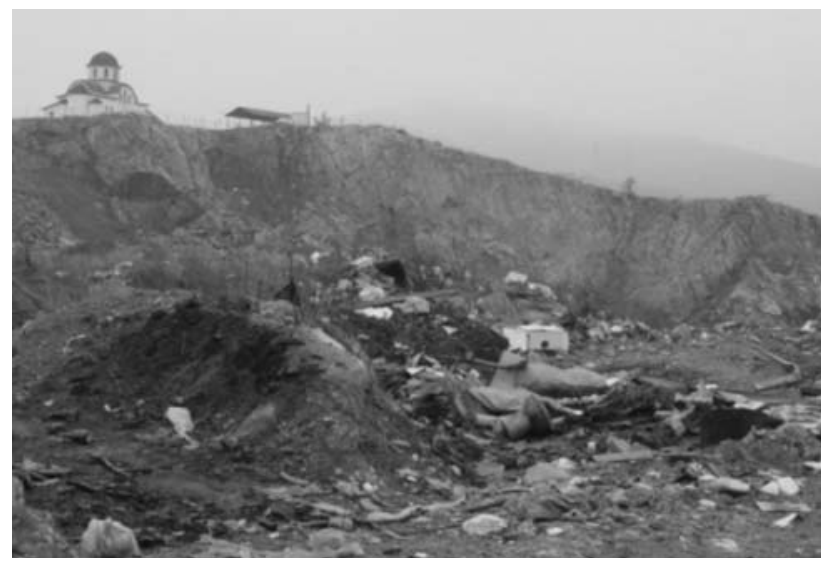

Fig. 1: Uncontrolled waste dump in an abandoned quarry (Kozani).

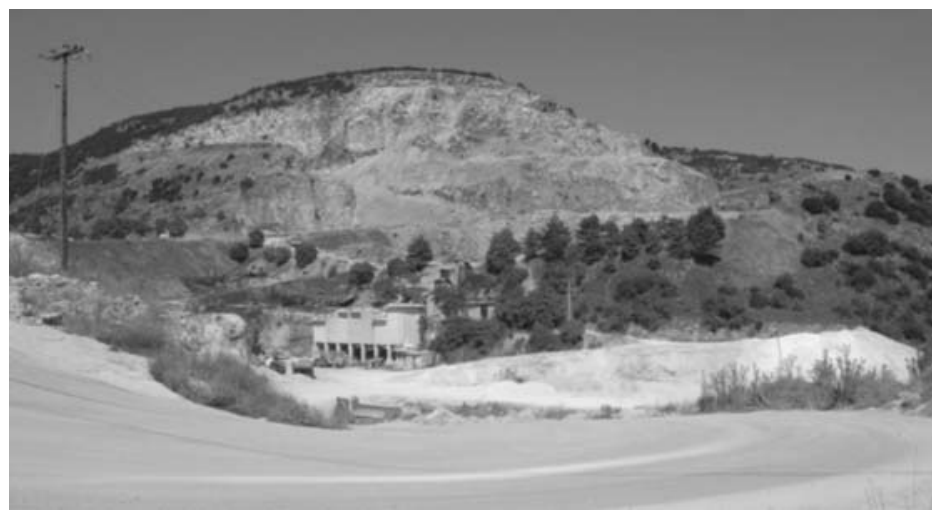

Fig. 2:Visual disturbance from abandoned quarry excavation (Ioannina).
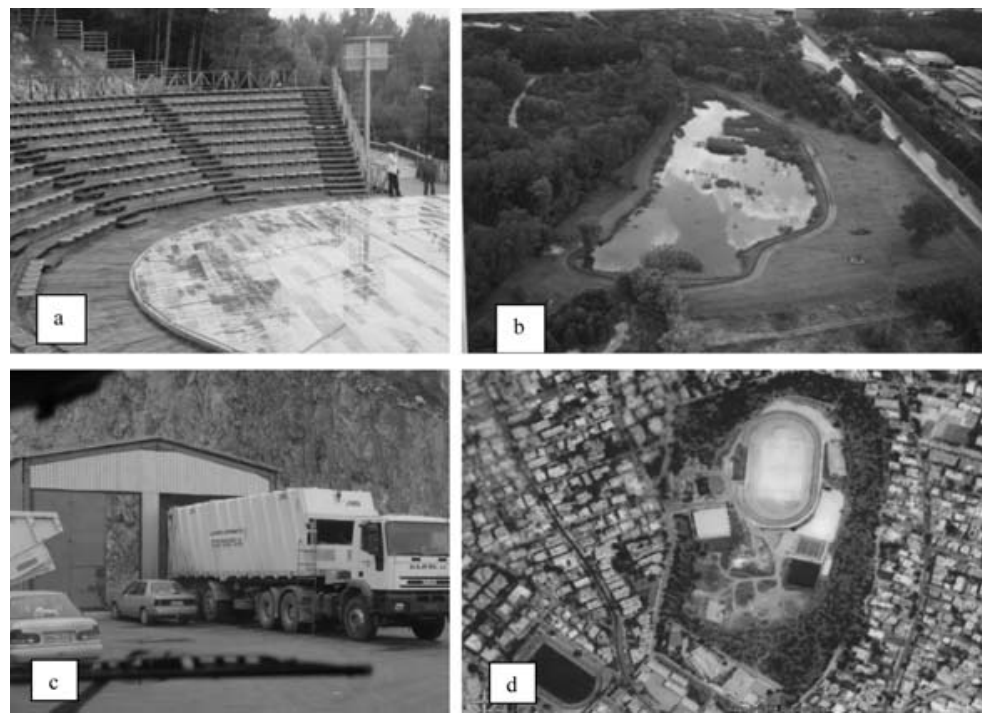

Fig. 3: Alternative plans for abandoned quarry rehabilitation (a. theatre, b. reforestation/recreation park, c. litter tranship station, $d$. athletic centre. 
ministrative entity. Using multi-criteria analysis and geographical information system we have concluded in a quick and cost effective method for the hierarchical classification of restoration sites. The establishment of an adequate set of criteria for the priority list is of main importance for the successful application of the method.

\section{Scope}

Taking into consideration all the aforementioned, a project was formulated, within the Third Community Support Framework, aiming to provide a methodological tool for use by the local administration authorities, at any level, in order to acquire a priority intervention list and select the most appropriate rehabilitation solution for abandoned quarries located in their region, taking into account environmental, social and economic criteria based on their priorities and their economic and technical potential.

\section{Methodology}

It is well known that there is no systematic recording of the quarrying activity at central level and for the granting of operating concessions a number of public authorities are involved (Prefectures, Mining inspectorate Agencies, Dpts of Industry and Mineral Wealth of the Regional Administration), varying according to the ownership status of the land (public of private) and the commodity produced (Marble, aggregates etc.). Thus, abandoned quarries, especially if they are more than a decade old, are often of "unknown identity", that is to say it is almost impossible to find concrete elements for the period of operation, the exploiter or their property arrangement. That made necessary a first phase for the survey of abandoned quarries and the localization of the quarry sites.

\section{Selection of pilot areas}

The following five representative districts were selected taking into account, besides the former extensive quarrying activity, the size of the urban centres, namely the following:

\section{Prefecture of Achaia \\ Prefecture of Ioannina \\ Prefecture of Drama \\ Region of Western Macedonia \\ Prefecture of Attica}

\section{Phase I: Survey of abandoned quarries - Creation of a Data Base}

In the selected regions, with the assistance of the Regional Administration, the Prefectures and local Municipalities, a survey of abandoned public quarries was carried out. A questionnaire was

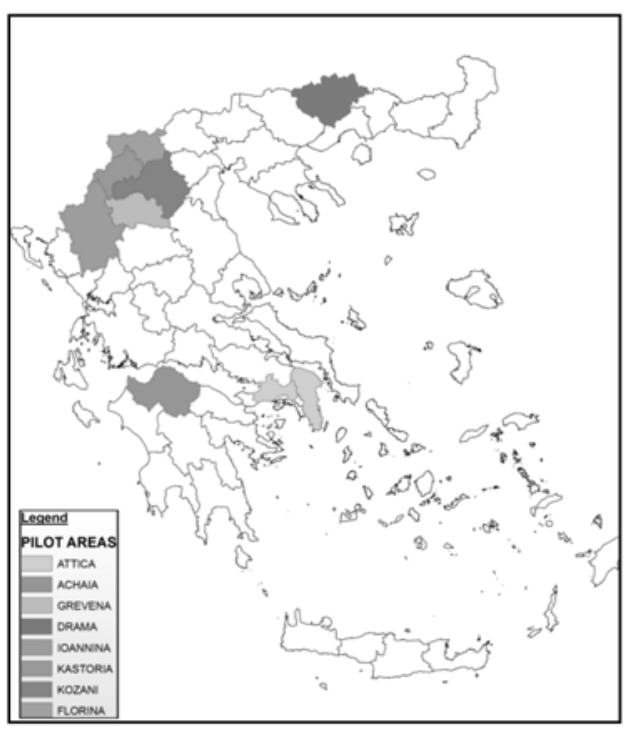
drawn up with data related to the geographic site, the area, the access and the orientation of each quarry, its morphology, as well as data on the soil, 
the climate, the fauna and flora of the region. Furthermore, geological, mineral, hydro geological, hydrological, geotechnical and ground characteristics, land uses in the direct and wider environment of the quarry were also recorded, as well as the population (size, economic activity etc) and the deficiencies in communal facilities.

\section{Phase II: Hierarchical classification of abandoned quarries for restoration}

The application of, well established or most up to date, rehabilitation solutions for quarry sites, can not be carried out simultaneously, due mainly to luck of the necessary funds. Therefore the selection of specific criteria is necessitated for the compilation of a priority list concerning the most urgent intervention for quarry sites rehabilitation.

Using multi-criteria analysis and GIS we concluded in a quick and cost effective method for the hierarchical classification of restoration sites. The establishment of an adequate set of criteria for the priority list is of main importance for the successful application of the method.

The application of criteria, with determined factors of importance, can set the quarries of a district in order of precedence and consequently lead to the rational planning of feasible rehabilitation solutions.

The following criteria were set for the establishment of a priority list (Table 1., Figure 6.) of inert quarry sites restoration/ rehabilitation, at any administration level, with the corresponding measurement index:

\section{A. The intensity of the pollution problem}

Three criteria were used, ground water pollution hazard, safety hazard and visual disturbance, for the calculation of the environmental problem caused by abandoned quarries:

\section{Ground water pollution /Health hazard}

- The use of the site as a waste dump and the sort of the deposited waste (inert, municipal or industrial/dangerous)

- The permeability of the quarry rocks

\section{Safety hazard}

- Quarry site hazard (slope and face stability etc.)

- Accessibility of the site (protective fencing, distance from roads and populated areas)

Visual disturbance (Figure 4)

- Extent of visibility

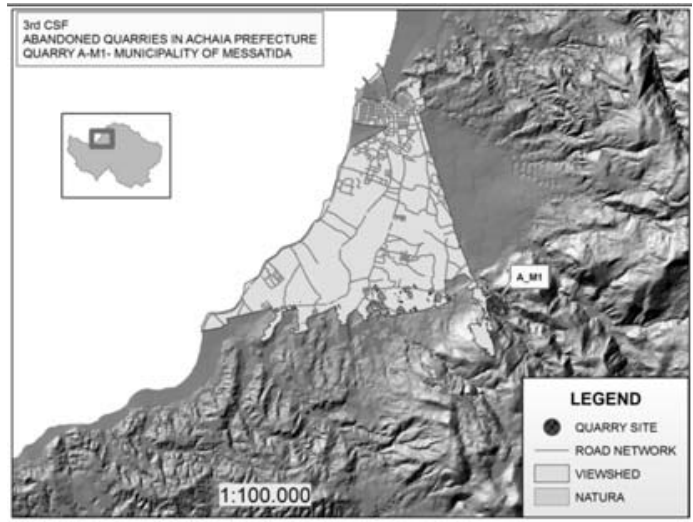

Fig. 4: Calculation of the visual disturbance indicator with the use of Geographical Information System. 


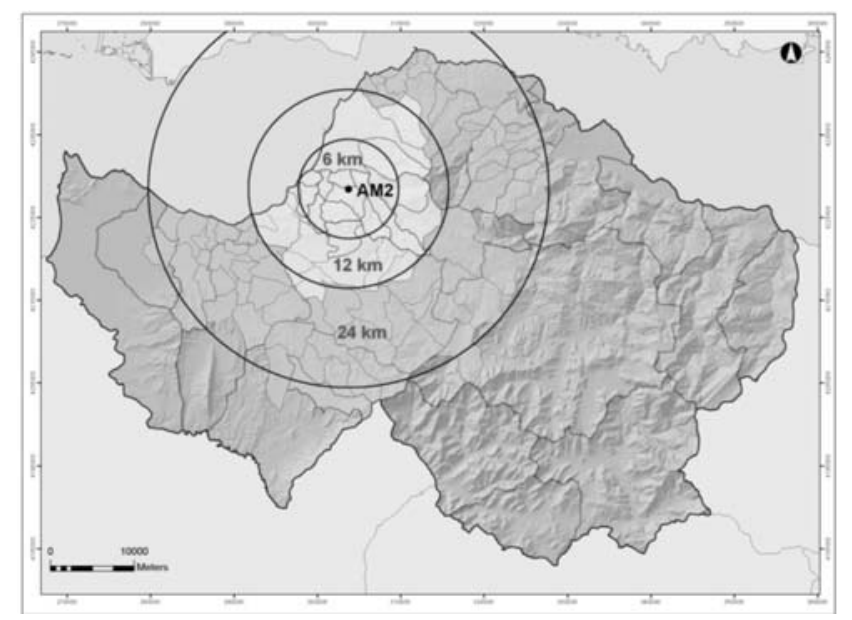

Fig. 5. Calculation of the population indicator with the use of Geographical Information System.

- The population included in this extent

- The length of national roads network included in this extent

- The presence of special protection areas (NATURA, archaeological sites etc

\section{B. The adequacy of the quarry site for communal facilities}

Two criteria were considered adequate for the evaluation of quarry sites as far as their competence for communal facilities is concerned:

- The area of the quarry site

- The distance and the accessibility from neighbouring settlements as well as the population size that could be possibly serviced (figure 5.)

\section{PHASE III: Selection of the optimal rehabilitation solution for specific quarry sites}

For this purpose a methodology of gradual approach was followed, including the following 5 steps:

1. Detailed examination of the quarry site, legal status, ownership status, topographic chart, geometrical characteristics, geological, hydro geological, geotechnical and environmental data.

2. Recording of deficiencies in infrastructure and communal facilities at local and peripheral level. Initial approach of feasible alternative solutions, based on permissible land use

3. Limitation of the number of alternative solutions based on restrictive/prohibitive conditions, for every solution under consideration, and the specific conditions of the quarry site under examination.

4. Modulation of distinct alternative rehabilitation plans and their detailed description.

5. Assessment of the alternative plans with Multi-criteria Analysis. Consultation with the directly involved parts (citizens, municipality, local organizations and associations). Formulation of the final list of alternative plans and their scores. 


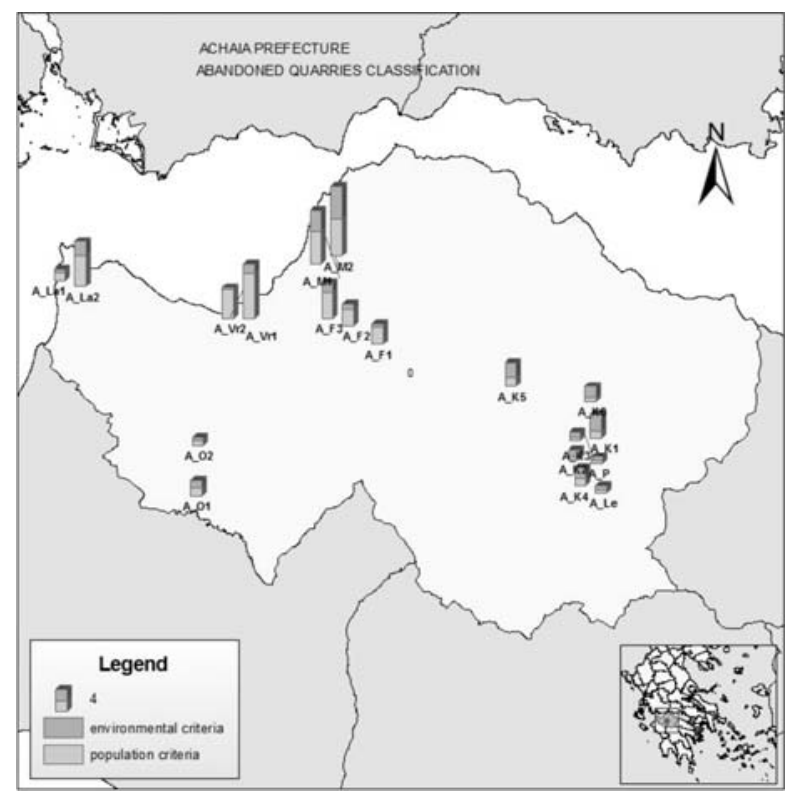

Fig. 6. Abandoned quarry sites in Achaia prefecture and their ranking with environmental and population criteria.

Table 1. Quarry site scoring according to environmental and population indicators

\begin{tabular}{|c|c|c|c|c|c|c|c|c|c|}
\hline QUARRY & GR.WATER & SAFETY & VISUAL & TOTAL & AREA & POPULA- & TOTAL & TOTAL & RANK \\
& HAZARD & HAZARD & DISTURBANCE & $\mathbf{1}$ & & TION & $\mathbf{2}$ & & \\
\hline A_Vr1 & 0 & 6 & 0,002 & 1,80 & 10 & 5,94 & 7,97 & 4,27 & 3 \\
\hline A_Vr2 & 0 & 1 & 0,002 & 0,30 & 4,5 & 5,94 & 5,22 & 2,27 & 7 \\
\hline A_K1 & 0 & 10 & 0,492 & 3,10 & 1,5 & 0,96 & 1,23 & 2,35 & 6 \\
\hline A_K2 & 0 & 2 & 2,762 & 1,15 & 0,3 & 0,88 & 0,59 & 0,93 & 15 \\
\hline A_K3 & 0 & 2 & 2,542 & 0,96 & 0,2 & 0,92 & 0,56 & 0,80 & 16 \\
\hline A_K4 & 0 & 6 & 0,225 & 1,85 & 2 & 0,86 & 1,43 & 1,68 & 10 \\
\hline A_K5 & 1 & 6 & 1,834 & 2,67 & 1,5 & 1,51 & 1,50 & 2,20 & 8 \\
\hline A_K6 & 0 & 6 & 0,416 & 1,88 & 0,2 & 1,52 & 0,86 & 1,47 & 12 \\
\hline A_La1 & 0 & 2 & 0,168 & 0,63 & 2 & 1,00 & 1,50 & 0,98 & 14 \\
\hline A_La2 & 0 & 6 & 3,428 & 2,49 & 10 & 1,02 & 5,51 & 3,70 & 4 \\
\hline A_Le & 0 & 2 & 0,368 & 0,67 & 0,4 & 0,63 & 0,52 & 0,61 & 19 \\
\hline A_M1 & 0 & 10 & 3,684 & 3,74 & 2,4 & 9,25 & 5,83 & 4,57 & 2 \\
\hline A_M2 & 4 & 10 & 4,185 & 5,84 & 3,5 & 9,80 & 6,65 & 6,16 & 1 \\
\hline A_P & 0 & 2 & 0,464 & 0,69 & 0,5 & 0,61 & 0,55 & 0,64 & 18 \\
\hline A_F1 & 0 & 2 & 0,187 & 0,64 & 1 & 5,03 & 3,01 & 1,59 & 11 \\
\hline A_F2 & 0 & 2 & 1,591 & 0,92 & 0,6 & 5,59 & 3,10 & 1,79 & 9 \\
\hline A_F3 & 0 & 2 & 5,486 & 1,70 & 3,2 & 6,16 & 4,68 & 2,89 & 5 \\
\hline A_O1 & 0 & 2 & 3,301 & 1,26 & 2 & 1,00 & 1,50 & 1,36 & 13 \\
\hline A_O2 & 0 & 2 & 0,321 & 0,66 & 0,3 & 1,30 & 0,80 & 0,72 & 17 \\
\hline
\end{tabular}


Table 2. Selection criteria for optimal quarry rehabilitation planning.

\begin{tabular}{|l|}
\hline Local/ peripheral needs \\
\hline Requirements of each solution in space and infrastructure \\
\hline Operating cost/ Maintenance cost \\
\hline Investment cost/economic limitations of the operator \\
\hline Technical requirements/ capabilities \\
\hline Environmental impacts \\
\hline Legal framework limitations \\
\hline Possibility of combination of different solutions \\
\hline Compatibility with the development plan of the district \\
\hline
\end{tabular}

The selection criteria for the optimal rehabilitation plan for each quarry site under examination are presented in Table 2.

\section{Conclusions-Results}

A great number of abandoned quarries (aggregates, decorative rocks and industrial minerals) are located, more or less, throughout the country. Some renters continue their suspended operation under the pretext of site restoration. Other quarries have been abandoned in the restoration capabilities of the nature. Quite a few have been used as uncontrolled waste dumps, thus becoming a major focal point for severe environmental pollution.

During the last 30 years, a growing interest for the rational management of the quarrying activity, as well as the restoration of the abandoned quarries, appears by the local authorities. It became at last common belief that the operation of a quarry has severe impact on the natural environment and can damage the environmental balance (natural relief, water resources, soil, flora and fauna). The legislation for quarry exploitation takes into account the protection of the natural environment and becomes stricter all over Europe, establishing more environmental restrictions for the quarrying activity.

The gradual restoration/ exploitation of abandoned quarry sites with local intervention can contribute to the amelioration of the environmental quality into and in the surroundings of the cities and towns and can be included in the regional development planning.

The abandoned quarry excavations indicate recent irrational quarry exploitation. Very high and steep slopes and irregular levels are a very common image leading in safety hazards (rock falls mass movement).The adverse impact on the environment is obvious, while the problem is enlarged in the vicinity of large urban centres, in the boundaries of which many aggregate quarries are often found.

Apart from the excavation activity a major aesthetic violence of the landscape is caused by the residues of the processing plants, especially the fines, as well as during the construction of the roads networks.

The proposed methodology on adequate quarry sites selection and determination of the most suitable rehabilitation solution proposed in the present study can constitute a useful tool for the local administration at any level. The compiled database can be enriched with new data, concluding from the materialization of the proposed solutions. 


\section{Acknowledgments}

This study was conducted within the Third Community Support Framework of IGME and was financed 50\% from the E.E.C and 50\% from the Hellenic State.

\section{References}

Beinat, E. (Editor), Nijkamp, P. 1998. Multicriteria Analysis for Land-Use Management, Springer.

Belton, V., Stewart, T., 2002. Multiple criteria decision analysis: an integrated approach. Dordrecht: Kluwer Academic Publications.

Damigos, D., Kaliampakos, D., 1999. Using Environmental Economics to Evaluate Quarry Rehabilitation Alternatives. Proceedings of the 6th International Conference on Environmental Science and Technoligy, Vol. B, pp. 514-521, Pythagorion, Samos, Greece.

Diakoulaki, D., 2006. System Analysis and Decision Making, National Technical University, Dpt of Chemical Engineers, Laboratory of Industrial and Energy Economics, September 2006.

Hatzistathis A., Spikoudis I., 1992. Protection of Nature and Architecture of Landscape. Book Edition,Thessaloniki.

Hinloopen, E., Nijkamp, P., Rietveld, P., 1983. Qualitative Discrete Multiple Criteria Choice Models, Regional Planning, Regional Science and Urban Economics 13.

Kaliampakos, D., Damigos, D., 1998. Quarry Rehabilitation in Attica. Mining Environmental Management, Vol. 6, No 1, pp. 13-14.

Kaliampakos, D.C., Panou, D.G., Damigos, D.G, 1999. Integrated Multicriteria and Cost - Benefit Analysis Methodology for Appraisal of After - use Plans for Quarries in Urban Areas. International Mining and Minerals, Vol. 2, No 15, pp. 67-74, March 1999.

Kaliampakos, D., Damigos, D., 2006. Developing fuzzy AHP system to evaluate rehabilitation alternatives of asbestos industrial complex

Menegaki, M.,Kaliampakos, D., 2005. Surface Mining Design: a systematic Approach to the evaluation of Visual Impacts, Proceedings of the International Conference on Mining and the Environment, Metals and Energy Recovery, securing the Future, Vol.2, pp.716-725, Skelleftea, Sweden, 27 june-1 july 2005.

Menegaki, M.,Kaliampakos, D., 2006. Lanscape Analysis as a tool for Surface Mining Design, Environment and Planning B:Planning and Design, 2006, volume 33, pp 185-196

Nijkamp, P., Rietveld, P., Voogd, H., 1990. Multicriteria Evaluation in Physical Planning, Contributions to Economic Analysis; 185, North-Holland, Amsterdam.

Saaty, T.L., 1980. The Analytic Hierarchy Process, New York : McGraw-Hill, 1980.

Saaty T. L., 1990. Multicriteria Decision Making. The Analytic Hierarchy Process, RWS Publications, Pittsburgh PA, USA, Second Edition. 